\title{
Gobierno y gubernamentalidad en el campo de estudios sobre infancias Aproximaciones a sus usos y aportes teórico-metodológicos ${ }^{1}$
}

\author{
Government and Governmentality in the Field of Childhood Studies. \\ Approaches to their Uses and Theoretical-Methodological Contributions
}

\section{Diana Alejandra Aguilar Rosero* \\ (iD) https://orcid.org/0000-0002-1323-3976}

\section{Tipo de Artículo: Informes de Investigación y ensayos inéditos}

\section{Doi: 10.17533/udea.unipluri.20.2.08}

Aguilar Rosero, D. A. (2020). Gobierno y gubernamentalidad en el campo de estudios sobre infancias. Aproximaciones a sus usos y aportes teórico-metodológicos. Uni-Pluriversidad, 20(2), e2020208. doi:

10.17533/udea.unipluri.20.2.08

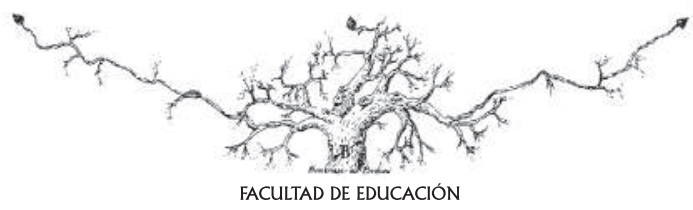

Recibido: 2020-03-26 • Aprobado: 2020-12-22

* Profesora de la Facultad de Educación de la Universidad de Antioquia. Doctora en Ciencias Sociales, Niñez y Juventud de la Universidad de Manizales y el CINDE e integrante del grupo de investigación Historia de la Práctica Pedagógica en Colombia.

Email: diana.aguilar@udea.edu.co 


\title{
Resumen
}

El campo de estudios sobre las infancias es una noción que permite dar cuenta de la pluralidad que caracteriza la producción de saber alrededor de este tema. Se evidencia su funcionamiento inter y transdisciplinar, y su carácter político y tensional que busca atravesar fronteras disciplinares y epistémicas. En este contexto, se plantea una reflexión sobre el uso de las nociones de gobierno y gubernamentalidad como herramientas analíticas con potencia para dinamizar la producción de saber al interior de este campo.

Palabras clave: gobierno, gubernamentalidad, campo de estudios sobre infancias

\begin{abstract}
The field of childhood studies allows to know the plurality from the production of knowledge around this issue. It evidences an inter and transdisciplinary functioning, and its political and tensional character that seeks to cross disciplinary and epistemic boundaries. In this context, a reflection on the use of notions of government and governmentality is proposed as analytical tool that enhances the production of knowledge in this field.
\end{abstract}

Keywords: government, governmentality, childhood studies. 


\section{INTRODUCCIÓN}

Desde los años noventa, en América Latina ha tenido lugar una proliferación de estudios e investigaciones de diversas procedencias disciplinares y epistemológicas sobre la infancia. Académicos como Carli (2011), Llobet (2011), Marín (2011), Amador (2012a), Barreto (2014), plantean la emergencia de nuevas agendas temáticas de investigación en ciencias sociales y educación sustentadas en una lectura problematizadora acerca de la infancia como construcción social y cultural. Esta parte de la mirada histórica como un referente importante para agudizar el análisis e identificar las transformaciones, discontinuidades, tensiones y contradicciones que han tenido lugar respecto a la forma de comprender e intervenir sobre los niños y niñas en nuestras sociedades.

La pluralidad de estas producciones, en parte estimulada por la promulgación de la Convención Internacional de los Derechos del Niño - CIDN—, se plantea hoy como un campo plural que escapa a la clasificación disciplinar y a todo intento unificador. Es así, como algunos académicos han sugerido la noción de campo como una opción para abarcar la proliferación de posturas y la dispersión de reflexiones alrededor de los procesos sociales, culturales y políticos en los que se inscriben las infancias en la región, sin pretender su unificación.

La noción de campo es propuesta por varios autores para dar cuenta de la diversidad de estudios, investigaciones, discursos y prácticas sobre las infancias. Nociones como campo de estudios sobre la infancia
(Carli, 2011), campo de problemas de la ninez (Llobet, 2011), campo de los estudios sociales de la infancia (Voltarelli y Nascimento, 2019), campo de investigación de la infancia (Díaz, 2012) campo infancias (Amador, 2012a) o campo discursivo de la infancia (Marín, 2011) cuentan con elementos distintivos de acuerdo con los contextos históricos, sociales y culturales de cada país y con las posturas teóricas en las que se inscriben; sin embargo, se reconocen en sus reflexiones algunos puntos de encuentro frente a la potencia de la noción de campo para analizar, problematizar y nutrir las reflexiones y actuaciones respecto al lugar que se le ha otorgado a las infancias en la región.

En primer lugar, la noción de campo permite relacionar lo disímil, por lo que el campo de estudios sobre las infancias se entiende como "un espacio complejo e interdisciplinario, que pretende articular múltiples recortes, perspectivas teórico-epistemológicas de difícil reunión, tradiciones investigativas diversas. Incluso, el lugar que ocupa "la niñez" como sujeto central es también multívoco." (Llobet, 2011, p.2). La articulación no se refiere a unificar concepciones sobre la infancia, ni sus formas de abordaje, por el contrario, implica reconocer la pluralidad de la construcción académica. Sin embargo, esta pluralidad no consiste en un agregado de conocimientos dispersos, sino en un espacio heterogéneo que al mismo tiempo es dinámico y móvil, en el que se entretejen relaciones de todo tipo, sea de semejanza, de contradicción, tensión, oposición o lucha que permiten visibilizar unas propuestas teó- 
ricas o metodológicas más que otras en unos momentos históricos particulares.

Desde la perspectiva de Sandra Carli, el campo de estudios sobre la infancia se caracteriza por su interdisciplinariedad. En el caso de Argentina, la producción académica en torno a la infancia desde la década de los noventa provino de distintas disciplinas como el psicoanálisis, la pedagogía, la sociología, el derecho, el trabajo social, los estudios literarios, de la comunicación y la cultura, la antropología y la antropología de la educación, de la historia y la historia de la educación. Esto muestra que el campo no se puede unificar en una sola disciplina, sino que cuenta con una pluralidad de saberes que hacen más porosos los límites disciplinares, atendiendo a un funcionamiento inter y transdisciplinar. Asimismo, la diversidad del campo evidencia que la producción de conocimiento sobre las infancias tiene lugar tanto dentro como fuera de las disciplinas, es decir, en sus márgenes (Carli, 2011), puesto que su heterogeneidad abarca prácticas de diversos órdenes no solo producciones académicas, también saberes de distinta procedencia y de diferentes niveles de elaboración alrededor de la infancia (Marín, 2011). En esta dirección, un campo de las infancias se configura más allá de las disciplinas, siendo lo político y lo cultural elementos que igualmente lo constituyen.

En segundo lugar, respecto a las características del campo de las infancias, desde estos autores latinoamericanos, consiste en el interés por articular tanto la producción de conocimiento como la formulación de políticas públicas y la acción política. Pensar en términos de campo permite reconocer que su funcionamiento y las maneras en que produce y circula los saberes sobre la infancia no es neutral (Llobet, 2011). Las tensiones, luchas y relaciones de poder entre los saberes expertos, los procesos de legitimación y las formas de institucionalización de los discursos dan cuenta de su funcionamiento no neutral; en su interior se debate la definición de perspectivas disciplinares, de las posiciones de sus actores y de saberes y representaciones, "que acarrean formas de actuar, contribuyendo a orientar ulteriores estrategias" (Díaz, 2012, p.50).

En palabras de Díaz (2012), el campo investigativo de la infancia podría entenderse como un "campo de producción simbólica" (p.51), esto es, como un escenario que genera discursos respondiendo a tensiones internas y presiones externas económicas y políticas que configuran la realidad social y producen subjetividades, formas de ser y estar en el mundo. Este interés crítico y problematizador del campo de estudios sobre las infancias en América Latina responde a unos intereses propios con relación a otras latitudes, como Europa y América del Norte. Como lo afirman Alvarado y Llobet (2013), una particularidad de la región consiste en las estrechas relaciones existentes entre la población infantil y las condiciones de pobreza, la reproducción intergeneracional de estas condiciones y las formas de desigualdad asociadas con la colonialidad y con las formas de la geopolítica mundial. Por tanto, muchos de los estudios adelantados en el campo buscan problematizar los discursos y prácticas que configuran las formas de desigualdad, subordinación, subalternidad, segregación y exclusión de los niños y niñas en la región.

Asimismo, en América Latina se han consolidado y ampliado estudios de un carácter más microsocial, lo que posibilita 
"reconstruir los matices, la heterogeneidad y la conflictividad interna de la intervención estatal, de la experiencia de la infancia, de la interpelación institucional, recuperando los mundos de la vida y los significados de los actores" (Llobet, 2011, p.11). Si bien, esto ha contribuido a visibilizar otras formas de comprender a los actores y sus experiencias, es un reto para el campo articular "las regularidades que se ubican claramente como el contexto de la experiencia y los procesos sociales de producción y legitimación de las mismas" (Llobet, 2011, p.12), es decir, que las experiencias de los actores no se vean solo como contexto, sino que hagan parte de la reconstrucción de los procesos sociales.

En tercer lugar, la noción de campo posibilita comprender la complejidad de los sujetos infantiles y de las infancias contemporáneas. Los distintos trabajos producidos al interior del campo de las infancias han mostrado, como lo señalan Voltarelli y Nascimento (2019), que hay un distanciamiento de la concepción universalista que consideraba la infancia como una categoría homogénea configurada en dos vías: los alumnos y los menores. Las investigaciones y reflexiones desarrolladas en el campo dan cuenta de la existencia y funcionamiento de una amplia diversidad de experiencias infantiles. Entre ellas se destacan: la preocupación por los hijos de desaparecidos, por el trabajo infantil y los niños en situación de calle; los niños de sectores populares, de sectores rurales, de comunidades indígenas u otros ámbitos multiculturales, nuevas formas de subjetividad y de identidades infantiles en relación con el consumo infantil, la cultura televisiva y la globalización.

También se reconoce su historicidad, es decir, la manera como se ha configurado la infancia y sus formas de relacionamiento social, cultural e institucional, posibilitando reconceptualizar las imágenes y construcciones sobre este objeto de saber y de gobierno, que no busca unificar la mirada sobre la niñez, sino reconocer sus distintos rostros a modo de una "quimera infantil contemporánea” (Marín, 2011, p.71) o, como lo sugiere Amador (2012a), reconocer las “infancias". La primera opción propone una metáfora que explica la existencia de la infancia como conformada por distintos imaginarios, saberes y atravesada por nociones del pasado y las incertidumbres e interrogantes del presente. La segunda plantea superar la pretensión universalizadora de la categoría infancia, así se reconocen sus múltiples formas de transitar la niñez y el conjunto de experiencias que constituyen a los sujetos, lo cual es posible en el funcionamiento del campo.

Un último elemento para destacar, frente a las apuestas y desarrollos que han tenido lugar al interior del campo de estudios sobre las infancias, consiste en la posibilidad de atravesar fronteras disciplinares y epistémicas, permitiendo "un descentramiento de los sistemas de conocimiento predominantes en las ciencias modernas" (Amador, 2012a, p.81). Esto implicaría, en palabras de Amador, comprender "cómo se están llevando a cabo las luchas contemporáneas alrededor de la reinvención de la emancipación social" (2012a, p.83), soportar su reflexión en sus diferencias y divergencias, y dislocar la dicotomía de la cultura hegemónica que permita analizar la condición infantil contemporánea, entendida ésta como:

El conjunto de circunstancias sociales, subjetivas, epistémicas y políticas en las que se produce el tránsito de la infancia en singular (noción prototípica 
del proyecto de la modernidad) a las infancias (categoría analítica que da cuenta de la pluralidad de los mundos de vida de los niños y niñas en el tiempo presente). (p.74)

Este tránsito tiene lugar entre dos procesos histórico-culturales. El primero se refiere a la configuración societal que consiste en el modo como occidente buscó proteger y regular a los niños y niñas mediante la familia y la escuela. El segundo proceso consistió en la conformación de sociedades moderno-coloniales en América Latina que se concretó en la configuración de discursos y prácticas relacionadas con el racismo, sexismo, clasismo y patriarcalismo. Desde esta perspectiva, el concepto de campo se propone como un escenario de producción de conocimiento sobre y con los niños y niñas que se distancie de los discursos instalados por las ciencias modernas y se abra a otras perspectivas, como son las epistemologías del sur que permitan la organización teórica, metodológica y estratégica del campo, y posibilite identificar las matrices de poder que lo atraviesan, además de reconocer diversas formas de subordinación de los otros y nuevas formas de su subjetividad.

Además de las características del campo de estudios sobre las infancias presentadas, también se destaca el despliegue de herramientas teóricas y metodológicas muy plurales, en las que predominan los abordajes de la investigación cualitativa, especialmente de los estudios etnográficos y microsociológicos, sin faltar la investigación macrosocial y los estudios estadísticos (Voltarelli y Nascimento, 2019). En esta diversidad de herramientas también ha tenido un lugar importante aquellas de procedencia foucaultiana, específicamente, las nociones de gobierno y gubernamentalidad.

Este artículo aporta algunas reflexiones para reconocer la potencia que tienen las herramientas analíticas foucaultianas, de gobierno y gubernamentalidad, para abrir y dinamizar rutas de análisis que enriquezcan el campo de los estudios sobre las infancias. En coherencia con este propósito, se presentará un breve recuento sobre la procedencia teórica de estas categorías y se plantearán las reflexiones derivadas de la revisión de distintas investigaciones latinoamericanas enmarcadas en el campo de estudios sobre las infancias y que hacen uso de herramientas foucaultianas. Esta revisión consistió en una lectura temática dirigida a identificar el uso que se hace de dichas herramientas y las líneas analíticas que abren para nutrir el campo.

\section{GUBERNAMENTALIDAD: EMERGENCIA HISTÓRICA Y USOS METODOLÓGICOS}

El concepto de gubernamentalidad propuesto inicialmente por el filósofo francés Michel Foucault, que en un primer momento apuntó a dar cuenta de las formas de gobierno en el siglo XVI y a un proceso de gubernamentalización del Estado, no solo se concibe como un acontecimiento histórico de la emergencia de los Estados en occidente, sino que pasa a funcionar como una categoría analítica útil para indagar por las formas de gobierno contemporáneas, hasta el punto de consolidar un campo particular sobre estudios de la gubernamentalidad. 
La emergencia histórica que plantea Foucault de la práctica gubernamental, la desarrolla a partir de la descripción de tres racionalidades políticas que sustentaron su configuración: la Razón de Estado, el liberalismo y el neoliberalismo. El autor desarrolla estos asuntos en sus cursos en el College de France, entre los años 1977-1978 y 1978-1979 y se publican en español bajo los títulos: Seguridad, Territorio, Población y El Nacimiento de la Biopolitica, respectivamente.

En el curso de 1977-1978, Foucault expresa su interés por analizar la biopolítica. A partir de la cuarta clase, aborda el tema de lo que llamó historia de la gubernamentalidad. Como lo explica Castro-Gómez (2010), esta decisión se sustentó, en parte, por el interés que para el filósofo francés representó la emergencia de una nueva racionalidad en el ejercicio del poder, que se visibilizó en el siglo XVI, a partir de una proliferación de tratados y reflexiones acerca de las "artes de gobernar", donde se identificó una variedad en las formas de gobierno: el gobierno de sí mismo, de la familia, de los niños, de las almas y, específicamente, el gobierno de los Estados. Cabe destacar que las artes de gobernar hacían referencia a formas diversas de gobierno y que el gobierno de los Estados será considerado una modalidad más (Foucault, 1999).

Lo que Foucault muestra al referirse a la historia de la gubernamentalidad es el proceso en el cual el Estado se gubernamentalizó, es decir, la manera como incorporó una razón, unas prácticas, saberes y dispositivos particulares para gobernar a los hombres. Este proceso, según plantea, encuentra sus brotes iniciales en el pastorado cristiano $^{2}$ (Foucault, 2006, p.193). Lo que llama la atención del autor sobre pastorado cristiano son las técnicas particulares que desarrolló para la dirección de la conducta, que de algún modo permitirán entender la racionalidad del Estado moderno y, específicamente, la emergencia de una nueva racionalidad, que consistió en la Razón de Estado.

La Razón de Estado asumió como objeto de reflexión el Estado mismo. Es aquí donde aparecen los políticos para plantear una forma particular de planear, pensar y programar la especificidad del gobierno (Foucault, 2006, p.289). El conocimiento del soberano ya no se limitó al de la ley, sino que se amplió al conocimiento de todo aquello que involucra el Estado, como el territorio, los recursos naturales, tipo de población (Castro-Gómez, 2010, p.115), lo que va a implicar un conocimiento especializado.

La Razón de Estado haría alusión no a un orden natural o divino, como en el caso de la soberanía, sino que se basaría en el conocimiento del Estado mismo, por lo que mantener y conservar su orden e integridad para su fortalecimiento y permanencia sería su principal fin. En esta dirección, se hizo necesario el gobierno de la economía y de la opinión, puesto que, según esta racionalidad, era necesario pensar en el pueblo para evitar la sublevación, lo que implicaba, en su momento, evitar el hambre y controlar la opinión a través de tecnologías como el mercantilismo y la publicidad. A esto se incorporan dos dispositivos para fortalecer las fuerzas internas del Estado, ya no el incremento del territorio, y armonizarlas a partir de alianzas políticas, ya no la combinación de herencias a partir de alianzas dinásticas (Foucault, 2006, p. 339). El primero consistió en el dispositivo diplomático militar, que recogió tanto los tratados y acuerdos concertados en- 
tre los Estados para mantener un equilibrio entre varios países e impedir que alguno se hiciera más poderoso, como un cuerpo militar entrenado para la guerra, en caso de verse amenazados por otros países. El segundo dispositivo fue el de la policía, entendido como "el conjunto de medios a través de los cuales se pueden incrementar las fuerzas del Estado a la vez que se mantiene el buen orden de este" (2006, p.357); este dispositivo incorporó las tecnologías pastorales que se dirigían a la conducción de la conducta, dando lugar al interés por lo que los individuos hacen, incluyendo las necesidades de la vida, su salud, el trabajo y la circulación mercantil. La vida y la felicidad de los individuos se vuelve valiosa para el Estado.

En el siglo XVIII tienen lugar, en la reflexión teórica, críticas respecto a la $R a$ zón de Estado, las cuales empezaron a ser planteadas por los economistas y no por los expertos del derecho. Son los fisiócratas quienes proponen la necesidad de crear una limitación interna del arte de gobernar pues, hasta entonces, la limitación era extrínseca al Estado mismo; dicha limitación fue posible gracias a la economía política que buscaba reflexionar sobre las prácticas de gobierno, no para cuestionar su legitimidad o ilegitimidad, como lo haría el derecho, sino para analizarlas desde un punto de vista pragmático, a partir del cual se pregunta por los efectos que tienen ciertas decisiones, por el éxito o fracaso de las mismas: "la economía política calcula los efectos reales que puede tener una medida cualquiera de gobierno, pero teniendo en cuenta la naturaleza de aquellos fenómenos que deben ser gobernados" (Castro- Gómez, 2010, p.138).

En esta dirección, los fisiócratas plantean la existencia de una naturaleza propia de lo que se pretende gobernar, de los objetos de la acción gubernamental, una naturaleza que debe preservarse y respetarse. Por tanto, gobernar bien implicaría abstenerse de intervenir jurídicamente, permitiendo el curso natural de las cosas. De esta manera, se criticaba no el abuso de la soberanía, sino el exceso de gobierno (Foucault, 2007, p.29). En el marco de la racionalidad gubernamental tienen lugar los dispositivos de seguridad, los cuales se distinguen de dispositivos jurídicos y dispositivos disciplinarios, puesto que apuntan al gobierno de la población a través del "cálculo de probabilidades" (Foucault, 2006, p.40) y ya no a la prohibición o permisión de las actividades económicas, ni a su normalización. Los dispositivos de seguridad intervienen de manera indirecta, es decir, buscan producir un medio, "en función de acontecimientos o de series de acontecimientos o elementos posibles, series que serán preciso regularizar en un marco polivalente y transformable" (Foucault, 2006, p.40). Desde esta perspectiva, lo que señala Foucault es un gran cambio en las técnicas de gobierno, puesto que se introduce "un gobierno que presupone la libertad de aquellos que gobierna" (Castro-Gómez, 2010, p.77), lo que daría lugar a la comprensión de la emergencia del liberalismo.

Al respecto, gobernar desde el liberalismo consistía en dejar que los individuos fueran libres según sus deseos e intereses puesto que "ellos saben lo que hacen". El conocimiento ya no está en el "conocimiento adecuado" que el soberano tenga sobre las cosas, son los individuos quienes saben lo que quieren; por ende, gobernar implica respetar la naturalidad de los intereses. Aquí se señala que lo que explica la obediencia de los individuos a las leyes consiste en un cálculo de intereses, es así como el individuo al 
hacer ese cálculo podrá ser capaz de gobernarse a sí mismo (Castro-Gómez, 2010). Lo que se puede observar desde la racionalidad liberal es que esta presupone la capacidad del individuo para autogobernarse, de actuar independiente del Estado, sin embargo, esto no implica un no gobierno, sino que esta gubernamentalidad más que reglamentar, gestiona la libertad de los individuos; es decir, se hace una intervención sobre el medio, sobre las condiciones de libertad, mediante el cálculo racional (2010, p.153).

Siguiendo la pista del liberalismo, Foucault da un "salto de dos siglos" (2007, p.97), para el análisis de la emergencia de un nuevo liberalismo en el siglo XX. El neoliberalismo correspondería a una nueva racionalidad de gobierno, visibilizada en dos escuelas: el ordoliberalismo alemán y el neoliberalismo norteamericano. Ambas escuelas tuvieron en común el rechazo del dirigismo estatal pero, a diferencia del liberalismo clásico, consideraban que el mercado no era una realidad natural que había que dejar fluir, por lo que defendían una forma particular de intervención; de este modo, el neoliberalismo no plantearía ni una regulación estatal de la economía ni una desregulación absoluta del mercado, al ser condiciones peligrosas para la libertad (Castro-Gómez, 2010), sino que respondería a una racionalidad y a unas tecnologías de gobierno particulares.

El neoliberalismo norteamericano de la Escuela de Chicago concuerda con los planteamientos de la escuela alemana respecto a un gobierno social que buscaba extender la competencia hacia los distintos ámbitos de la vida, no obstante, una de sus diferencias consistió en radicalizar esta postura planteando hacer de lo social una economía, convertir la vida social misma en un merca- do lo que implicaría una molecularización de la forma-empresa (Castro-Gómez, 2010). Es decir, no solo bastaría con el funcionamiento de la sociedad como empresa, en el marco de la competencia, sino que el sujeto mismo debía actuar como una empresa, superándose definitivamente la dicotomía entre lo económico y lo social y expresando esta apuesta en la teoría del capital humano.

A partir de la forma del capital humano, Castro-Gómez (2010) sugiere una ampliación de la biopolítica que Foucault identificó en el liberalismo clásico, puesto que ya no se limita a las variables biológicas (nacimiento, muerte, enfermedad), sino que involucra formas de gobierno de la vida íntima, decisiones cotidianas que se convierten en estrategias económicas dirigidas a que el sujeto se capitalice. Este funcionamiento biopolítico tendría como propósito "el gobierno de la intimidad" y la creación de un medio ambiente competitivo caracterizado por la inseguridad generalizada en la que los individuos asumirían como forma de vida el riesgo permanente que los conduciría a ocuparse de sí mismos y autogobernarse.

La emergencia histórica de aquello que Michel Foucault identificó como la forma en que el Estado se gubernamentalizó, explicada de manera esquemática en los párrafos anteriores, responde a formas de configuración del Estado moderno en el contexto particular de los países centro-europeos. Sin embargo, estas reflexiones se extendieron alimentando diversas líneas de investigación y haciendo de las nociones de gobierno y gubernamentalidad, categorías más generales y abstractas para ser usadas como instrumentos de análisis (Cortés, 2011, p.29). Muestra de esto lo constituye el campo de estudios de la gubernamentalidad, desarro- 
llado principalmente en el mundo anglosajón, cuyos investigadores continuaron y ampliaron el interés, planteado inicialmente por el filósofo francés, de indagar sobre las tecnologías neoliberales de gobierno que, si bien, él alcanzó a percibir cuando apenas despuntaban, los anglofoucaultianos verían ya en su plenitud (De Marinis, 1999, p.9). La categoría de gobierno y de gubernamentalidad se generalizan y se les otorga un uso metodológico; para esto es importante distinguir la delimitación conceptual de cada una de estas categorías. En cuanto a gobierno, en un sentido general, hace alusión a "la conducción de la conducta", es decir, implica unas prácticas que buscan afectar, intervenir, modificar la conducta de otros o de sí mismo (De Marinis, 1999, p.11); aquí se identifican dos ejes de esta noción, el primero consiste en la relación entre sujetos, y el segundo en la relación consigo mismo. Al respecto, citando a Foucault, Castro (2007) explica:

En el primer sentido, "[...] [el gobierno] es un conjunto de acciones sobre acciones posibles. Trabaja sobre un campo de posibilidad en el que viene a inscribirse el comportamiento de los sujetos que actúan: incita, induce, desvía, facilita o dificulta, extiende o limita, hace más o menos probable, llevado al límite, obliga o impide absolutamente. Pero es siempre una manera de actuar sobre uno o varios sujetos actuantes, y ello en tanto que actúan o son susceptibles de actuar. [...] en el segundo sentido, es también del orden del gobierno la relación que uno puede establecer consigo mismo en la medida en que, por ejemplo, se trata de dominar los placeres o los deseos". (Foucault, 1984, como se citó en Castro, 2007, p.11)

Por otro lado, la gubernamentalidad se compone de la palabra gobernar y del sustantivo "mentalidad" que, según De Marinis
(1999), remite a considerar en relación tanto el ámbito y el objeto de gobierno como la forma de pensar que debe emplearse para gobernar. En esta dirección, Castro (2007) afirma que para Foucault la noción de gubernamentalidad hace referencia "al objeto de estudio de las maneras de gobernar" (p.11), en otras palabras, la gubernamentalidad se interroga por las racionalidades que sustentan esas acciones que se ejercen para modificar las conductas de los otros y las propias. Lo interesante es notar que esta noción abarca un significado amplio sobre las formas de gobierno, que no se limita a las formas del Estado-nación, por el contrario, apunta a analizar las formas de gobierno prescindiendo del Estado. Como lo afirma Castro-Gómez (2010), se propone una analítica en la que es Estado es el "resultado inestable de una multiplicidad de prácticas históricas que deben ser estudiadas en su singularidad" y busca dar cuenta del "tipo de tácticas, técnicas y formas de conocimiento que son puestos en marcha para ejecutar ese gobierno" (p.245).

Por consiguiente, la noción de gubernamentalidad se generaliza y ya no solo define un acontecimiento histórico, sino que se reviste de un uso metodológico que posibilita otros análisis del ejercicio del poder y su relación con el saber y con los procesos de subjetivación. Como lo destaca De Marinis (1999), a los estudios de la gubernamentalidad les importa dar cuenta del "ejercicio real, material, el cómo del poder, codificado y expresado por racionalidades políticas y desplegado y efectivizado en tecnologías de gobierno" (p.14). Tres son entonces los elementos analíticos para considerar en el uso de la categoría: la racionalidad política, las tecnologías de gobierno y los procesos de subjetivación. 
La racionalidad política conduce a identificar las relaciones y tramas entre los diversos saberes, valores morales, justificaciones, elecciones, modos de pensar que configuran y atraviesan las prácticas en relación con el gobierno de la población. Por su parte, las tecnologías de gobierno aluden a la aplicación de los medios seleccionados para alcanzar unos fines dispuestos por la racionalidad política; estas abarcan la dimensión estratégica de las prácticas (Castro-Gómez, 2010), es decir, el modo en que tales prácticas operan al interior de un entramado de poder. El tercer elemento consiste en los procesos de subjetivación, entendiendo la subjetividad como un efecto del conjunto de juegos y procedimientos presentes en las relaciones de poder (Cortés, 2011); la subjetividad se constituye, entonces, en esa tercera categoría que no se reduce al poder ni al saber, puesto que aporta otro aspecto al análisis foucaultiano que consiste en reconocer las prácticas de libertad y las posibilidades de resistencia.

\section{APORTES DE LAS NOCIONES DE GOBIERNO Y GUBERNAMENTALIDAD AL CAMPO DE ESTUDIOS SOBRE INFANCIAS}

En este apartado se da cuenta de los aportes que el uso analítico de las nociones de gobierno y gubernamentalidad ofrecen al campo de los estudios sobre infancias. Para esto, se seleccionaron 16 investigaciones realizadas en países como Argentina, Brasil y Colombia que usaron como herramientas centrales para sus análisis las nociones antes mencionadas. El cruce de estos trabajos permitió identificar algunos elementos que abren líneas de trabajo a ser exploradas y profundizadas, además, aportan a la pluralidad del campo y a su interés por estructurar alternativas sobre el lugar de los niños y niñas en el mundo social.

Es importante señalar que en la mayoría de las investigaciones revisadas se privilegia el uso de la noción de gobierno por su amplitud y versatilidad, puesto que, como se afirmó anteriormente, esta noción alude a las formas de regular las conductas por la aplicación de medios técnicos. Se plantea como una noción pertinente para dar cuenta de un conjunto diverso de prácticas "dirigidas a guiar, administrar o regular la con- ducta de las personas, tanto propias como ajenas, a la luz de ciertos principios u objetivos" (Mussetta, 2009, pág.46). Por su parte, la gubernamentalidad implicaría reconocer las configuraciones históricas particulares y describir la relación entre las racionalidades políticas, las tecnologías de gobierno y los procesos de subjetivación en el marco de prácticas que involucran instituciones estatales y no estatales. Los aportes que se plantean a continuación responden a los usos analíticos de ambas categorías.

\section{Diversificación, problematización y desnaturalización.}

En un primer momento, se destaca que las investigaciones abordan temas diversos en relación con las infancias y de distintas procedencias disciplinares, como son los procesos de institucionalización de los derechos del niño y el paso hacia el paradigma de la protección integral (Magistris, 2016; Da Silveira, 2015), la producción de subjetividades infantiles como efecto de las 
modalidades de gobierno contemporáneas (Gadelha, 2013; Bujes, 2002; Gallo, 2015; Amador, 2009), las estrategias "gubernamentales" presentes en formas urbanísticas, arquitectónicas y espaciales propuestas para la infancia (Runge, 2016; Runge y Carrillo, 2013), las prácticas escolares y las tecnologías de gobierno en el marco de la formación de ciudadanos (Augusto, 2015; Reyes, 2012), las prácticas de gobierno en la tradición pedagógica (Marín, 2012; Pagni, 2015), y el análisis de las políticas y programas de atención y educación de la infancia y la familia (Fonseca, 2011; Bujes, 2015; Lemos, 2015; Anastasía, 2015). Asimismo, los abordajes metodológicos son variados: estudios de caso, trabajos etnográficos, investigación documental e investigación histórica. Esto muestra la necesidad de interrelacionar las categorías foucaultianas con otras formas de producción de conocimiento y con conceptos que enriquezcan las lecturas y reflexiones de las distintas investigaciones, lo que confirma la importancia de usar las herramientas de manera flexible y desde una lectura crítica.

Además de la diversidad temática, se identifica en las investigaciones el uso de la categoría de gobierno y gubernamentalidad como aspecto común para reconocer el "carácter contingente de los procesos sociopolíticos, asumiendo que nada está dado de antemano ni existe una verdad acerca de ningún fenómeno a priori" (Magistris, 2016, p.22). Es decir, partir de las prácticas de gobierno implicaría, según Foucault (2007), "una manera muy explícita de dejar de lado como objeto primero, primitivo, ya dado, una serie de nociones" (p.17) como Estado, infancia, derechos, familia, ciudadanía, protección, comunidad, sociedad civil, atención integral, entre otras. Además, posibilitaría centrar la mirada en las prácticas tal como aparecen, en las formas como nos relacionamos con los niños y niñas y en la manera como se racionalizan. De esta forma, se rompe con la naturalización del objeto, se problematizan los supuestos históricamente instalados y se diversifican las miradas que permitan entender cómo se configuran las distintas experiencias infantiles y la complejidad con la que se entrelazan las distintas racionalidades, saberes, discursos y relaciones de poder.

El uso de las nociones de gobierno y gubernamentalidad implica partir de las prácticas en sentido foucaultiano. Las prácticas existen en red y al mismo tiempo son singulares y múltiples, pero deben ser estudiadas en sus articulaciones y en función de unas reglas específicas, pues sus relaciones no son arbitrarias. El análisis de estas reglas conecta la lectura arqueológica-genealógica con el análisis de la gubernamentalidad (Castro-Gómez, 2010). En este sentido, los trabajos más que comprobar o verificar el cumplimiento de programas, políticas o discursos que se posicionan como hegemónicos, analizan las prácticas que tienen lugar en los contextos cotidianos y microsociales.

\section{La articulación entre lo macropolítico y lo micropolítico.}

Aunque el campo de estudios sobre infancias manifieste una importante afinidad por los estudios micropolíticos que se nutre desde la perspectiva aquí estudiada, las nociones de gobierno y gubernamentalidad permiten establecer un análisis que relaciona lo macro y lo micropolítico; los procesos de orden social, económico y estatal se entrecruzan con las prácticas locales, situa- 
das, capilares y con los procesos de subjetivación, es decir, "articula un nivel "molar" con uno "molecular"" (Papalini, Córdoba y Marengo, 2012, p.194). De esta manera, se establece una mirada distinta del poder que va más allá del Estado y de las relaciones de dominación. Esto es posible por el cruce analítico de racionalidades, tecnologías de gobierno y procesos de subjetivación.

Esta relación entre lo macro y lo micropolítico se evidencia en aquellos trabajos que interrogan los discursos que sustentan las políticas públicas de infancia y visibilizan las maneras como se despliegan dispositivos de gobierno y formas de modulación de la vida de niños y niñas, por ejemplo: los sistemas de protección de derechos del niño, niñas y adolescente y sus formas de institucionalización local (Magistri, 2016); o el Estatuto da Criança e do Adolescente (ECA) inscrito en el paradigma de la atención integral, a partir del cual se plantearon nuevas categorías sociales como infancia en condición de vulnerabilidad, joven infractor y medidas socioeducativas resultando en procesos de reordenamiento institucional caracterizados por una tensa y conflictiva coexistencia de formas híbridas de saber poder (Da Silveira, 2015). Las políticas y los discursos hegemónicos, más que entenderse como referentes incuestionables que deben ser aplicados, se comprenden como prácticas discursivas históricamente construidas, atravesadas por relaciones de poder en continua tensión que se entrelazan con modos de acción que involucran tanto la producción de sujetos como las prácticas de resistencia y libertad.

Por otra parte, la categoría de gubernamentalidad también explica la relación de las prácticas situadas con la transformación de la sociedad disciplinaria a una postdisciplinaria (Foucault, 1999). Es decir, ha favorecido los análisis del lugar de las infancias en la sociedad neoliberal (Gadelha, 2013; Bujes, 2015; Lemos, 2015), dando lugar a una reflexión más amplia de lo que algunos han llamado la emergencia de infancias contemporáneas.

\section{Analizar el Estado más allá del Estado.}

Otro aporte de las categorías de gobierno y gubernamentalidad, en estrecha relación con los apartados anteriores, consiste en la posibilidad de ir más allá del Estado, puesto que este "no es ni el centro organizador del poder político, ni el principio explicativo de las estrategias de gobierno" (Papalini, Córdoba y Marengo, 2012, p.198). Justamente, partir de las prácticas contribuye a alejarse del Estado como un ente preexiste o natural y entenderlo no como el origen del gobierno, por el contrario, como producto de "la objetivación de una serie de prácticas gubernamentales" (Castro-Gómez, 2010, p.45). El Estado en el marco de la gubernamentalidad se coloca junto a una variada cantidad de actores y dispositivos. (Mussetta, 2009) desdibujando las dualidades entre lo público y lo privado, lo externo e interno, Estado y sociedad civil. En esta dirección, Anastasía (2015) plantea con respecto a la reflexión sobre la infancia:

Los sentidos en torno a la infancia son regulaciones que no son definidas por un ente superior, más poderoso o jerárquico, como puede ser el Estado, la ley, la Organización de Naciones Unidas. [...] Al contrario, lo que nos proponemos pensar es que se explicita un complejo funcionamiento del poder que no permite asignar fuentes de producci- 
ón de sentidos o de emanación performática de valores, sino que permite ver el funcionamiento y las operaciones de los sentidos en la gestión del "interés general de la población". (p.8)

En esta dirección, se encuentra el trabajo de Lemos (2015), quien analiza prácticas concretas planteadas por la Unesco en relación con la comunidad y las familias brasileñas. El autor identifica, en la agenda de la Unesco, un proceso de cooptación de la participación social en el entrecruzamiento con el discurso del sujeto de derechos y de la redefinición de las funciones del Estado, dando lugar a unas tecnologías con fines utilitaristas de gobierno de la vida y de las conductas en pro de la economía y de un empresariamiento de lo social, sustentado en el activismo político de base comunitaria. Desde esta perspectiva se identifican las diferentes relaciones de saber-poder en las que se entretejen y redefinen las funciones estatales, que no se restringen a una lectura preestablecida del Estado, sino que involucra el juego de relaciones y tensiones con organismos internacionales, con la sociedad civil y con las comunidades.

De igual manera lo sugiere el trabajo de Fonseca (2011). Este se interesa por analizar las formas de legitimación de una política social dirigida a la atención de la primera infancia en el Brasil que producen, al mismo tiempo, regulaciones morales dirigidas a las madres desde el discurso del desarrollo infantil temprano. Antes que asumir al Estado como fuente de estos discursos, analiza el funcionamiento de "comunidades epistémicas" presentes en la dinámica global que favorecen la apropiación local de ciertas tecnologías de gobierno, que centran la mirada en el cerebro del recién nacido y en la actualización de un tipo de moralidad materna.

\section{Las subjetividades infantiles.}

Para comprender el cuarto aporte, cabe señalar que la categoría de gubernamentalidad le posibilitó al filósofo francés enfrentar las críticas realizadas a su trabajo en lo concerniente a la relación saber- poder. Se cuestionaba la categoría de poder como concepto omnipresente que no dejaba muchas posibilidades para pensar el lugar de los sujetos en relación con las prácticas de dominación, pues éstos, al ser concebidos como efecto de la relación saber-poder, se encontraban "sujetados" a unas disciplinas y a unos discursos de verdad.

En este marco de críticas, Foucault se interesó por encontrar una forma de análisis que le permitiera ampliar su mirada más allá de las dos categorías que desarrolló, saber y poder, y, abrir su horizonte analítico. La subjetividad se constituye, entonces, en esa tercera categoría que no se reduce al poder ni al saber, puesto que aporta otro aspecto al análisis foucaultiano que consiste en reconocer las prácticas de libertad y las posibilidades de resistencia. En este sentido, el concepto de gubernamentalidad recoge las tres categorías de saber, poder y subjetividad, que permite romper con el binomio dominación- resistencia, puesto que la gubernamentalidad no se reduce a un asunto de control y dominación del soberano o de las prácticas disciplinares, sino que esta categoría reconoce las prácticas de libertad de los individuos.

En este sentido, para los estudios en las infancias ha sido fructífero el uso de la noción de gobierno y gubernamentalidad para visibilizar los procesos de subjetivación, no solo en términos del gobierno de los otros, sino también, del gobierno de sí. Por una 
parte, se complejiza la mirada de la infancia al dar cuenta de la pluralidad de las distintas configuraciones de la experiencia infantil, que permite reconocer las complejidades, tensiones y matices de la infancia escolarizada, asimismo, visibilizar las formas de existencia de las infancias excluidas y estigmatizadas, la infancia pobre, los menores, la infancia vulnerable y reconocer la emergencia de otras formas contemporáneas de infancia.

Los procesos de subjetivación tienen lugar en las relaciones que se establecen con distintas prácticas, como es el caso de los dispositivos pedagógicos, materializados en el análisis que plantea Bujes (2002a; 2002b) sobre los Referentes Curriculares Nacionales para la Educación Infantil, mostrando cómo estos dispositivos despliegan unas formas de agenciamiento sobre el sujeto infantil dirigidas al autogobierno y sustentadas en unas tecnologías del yo. Por otra parte, los espacios sociales urbanizados diseñados para los niños se integran en una estrategia domesticadora, que modulan la experiencia infantil orientándola hacia el autocontrol, la individualización, los cuerpos "rutinizados" y la insularización del espacio vital (Runge, 2016). Igualmente, el trabajo de Amador (2012b) analiza las subjetividades y procesos de subjetivación de niños y niñas en relación con la cibercultura, identificando que estas prácticas permiten la creación de una extimidad dirigida al agenciamiento y a unas experiencias de sí que les permite hablar, pensar y reconquistar su propia historia.

Finalmente, a partir del recorrido anterior, en coherencia con el propósito de este artículo, se advierte que el uso teórico y metodológico de las nociones de gobierno y de gubernamentalidad alimenta y dinamiza las cualidades del campo de estudios sobre las infancias, puesto que favorece la pluralidad de las líneas de trabajo y el diálogo inter y transdisciplinar; contribuye a la acción política que busca el campo, aportando análisis dialógicos entre lo macro y lo microsocial; visibiliza prácticas cotidianas, mundanas y capilares. Además, aporta a la construcción de lecturas que rompen con la naturalidad de los objetos construidos, así estos hayan sido conquistas progresistas en un momento específico. Como lo plantea Veiga-Neto (2015), más que establecer juicios morales sobre las prácticas que involucran a las infancias, se trata de examinar cada una de ellas, someterlas a la crítica permanente y poner en práctica un "activismo pesimista" que implica cuestionarlo todo y desconfiar de todo, no solo para saber cómo son gobernados los niños y niñas y cómo estamos siendo gobernados, sino hacia dónde nos están conduciendo estas prácticas y cómo nos configuran como sociedad y, de esta manera, identificar los límites que nos circunscriben para seguir explorando formas de libertad posibles.

\section{Notas}

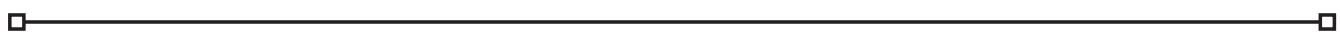

1. Este artículo se deriva de las reflexiones planteadas en el marco de la tesis doctoral titulada: $L a$ Configuración de la Atención de la Primera Infancia en Colombia como Práctica de Gobierno: Gubernamentalidad, Desarrollo y Neoliberalismo (1949-2007). 
2. Para Foucault, El pastorado cristiano es una forma particular de gobernar a los hombres, que dona a la configuración del Estado moderno unas técnicas que se caracterizan por plantear modos específicos de individualización (Foucault, 2006)

\section{REFERENCIAS}

Alvarado, S., y Llobet, V. (2013) Introducción. Pensar la infancia desde América Latina: un estado de la cuestión. CLACSO. 27-35

Amador, J. C. (2009) La Subordinación De La Infancia Como Parámetro Biopolítico Y Diferencia Colonial En Colombia (1920-1968). Nómadas. (31), 240-256.

Amador, J. C. (2012a). Condición infantil contemporánea: hacia una epistemología de las infancias. Pedagogía y Saberes. (37), 73-87.

Amador, J. C. (2012b). Infancias, subjetividades y cibercultura: neopolítica y experiencia de sí. $R e$ vista Cientifica, 1(15), 13-29.

Anastasía, P. (2015). Gubernamentalidad, Estado y regulaciones: apuntes para pensar el gobierno de la infancia. Actas I Congreso Latinoamericano de Teoría Social. Buenos Aires. Disponible en: http://diferencias.com.ar/congreso/ICLTS2015/ponencias/Mesa\%2020/ICLTS2015_Mesa20_ Anastas\%C3\%ADa.pdf

Augusto, A. (2015). Governando crianças e jovens: escola, drogas e violência. Michel Foucault: o governo da infância. Belo Horizonte: Autêntica, 11-24.

Barreto Ramírez, M. H. (2014). La infancia: aportes para pensar los desafíos de la investigación en el contexto latinoamericano. Infancias Imágenes, 13(2), 9-22

Bujes, M. I. E. (2002a). Governando a Subjetividade: a Constituição do Sujeito Infantilno RCN/E. Pro-Posições, 13(1), 163-175. Recuperado de https://periodicos.sbu.unicamp.br/ojs/index.php/ proposic/article/view/8643976

Bujes, M. I. E. (2002b) A invenção do eu infantil: dispositivos pedagógicos em ação. Revista Brasileira de Educação, n. 21, set-dez. Recuperado en: < http://www.scielo.br/pdf/rbedu/n21/n21a02. pdf $>$

Bujes, M. I. E. (2015). Políticas sociais, capital humano e infância em tempos neoliberais. Michel Foucault: O governo da infância. Belo Horizonte: Autêntica, 259-280.

Carli, S. (2011) El campo de estudios sobre la infancia en las fronteras de las disciplinas. Notas para su caracterización e hipótesis sobre sus desafíos. En: Infancias: Políticas y saberes en Argentina y Brasil. Siglos XIX y XX.

Castro, E. (2007) Biopolítica y Gubernamentalidad. Temas \& Matizes. (11), 8- 18.

Castro-Gómez, S. (2010) Historia de la gubernamentalidad. Razón de Estado, liberalismo y neoliberalismo en Michel Foucault. Bogotá: Siglo del Hombre, Pontificia Universidad Javeriana, Universidad Santo Tomás. 
Cortés, A. (2011). La noción de gubernamentalidad en Foucault: Reflexiones para la investigación educativa. En: Gubernamentalidad y educación: discusiones contemporáneas. Bogotá: Instituto para la Investigación Educativa y el Desarrollo Pedagógico -IDEP-. 151 p.

Da Silveira, D. S. (2015). Governamentalidades, saberes e políticas públicas na área de Direitos Humanos da criança e do adolescente. Michel Foucault: o governo da infância. Belo Horizonte: Autêntica Editora. 57-83.

De Marinis, P. (1999). Gobierno, Gubernamentalidad, Foucault y los Anglofoucaultianos. (O: un ensayo sobre la racionalidad política del neoliberalismo). Ramos y García (Comps.) Globalización, Riesgo y Reflexividad. Tres temas de la teoría social contemporánea. Madrid: Centro de Investigaciones Sociológicas.

Díaz Soler, C. J. (2012) Más allá de la infancia escolarizada. Elementos para una discusión sobre el campo investigativo de la infancia. Pedagogía y Saberes, (37), 49-62

Foucault, M. (2006). Seguridad, Territorio, Población: curso en el College de France (1977 - 1978$).$ Buenos Aires: Fondo de Cultura Económica, 484 p.

Foucault, M. (2007). El Nacimiento de la Biopolítica: curso en el College de France: (1978-1979). México: Fondo de Cultura Económica, 401 p.

Foucault, M. (1999). Gubernamentalidad. En: Estética, ética y hermenéutica: obras esenciales. Barcelona: Paidós. Pp. 175-198

Gadelha, S. (2013). Empresariamiento de la sociedad y el gobierno de la infancia pobre. Revista Colombiana de Educación, (65), 215-238.

Gallo, S. (2015). O pequeno cidadão": sobre a condução da infância em uma governamentalidade democrática. Michel Foucault: o governo da infância. Belo Horizonte: Autêntica, 329-343.

Lemos, F. C. S. (2015). A UNESCO e o governo da infância por meio do capital social: problematizando práticas de segurança. Michel Foucault: O governo da infância. Belo Horizonte: Autêntica, 115-126.

Llobet, V. (2011) Un mapeo preliminar de investigaciones sobre infancia y adolescencia en las ciencias sociales en Argentina desde mediados de la década de 1990. KAIROS. Revista de Temas Sociales, 15(28).

Magistris, G. (2016). El gobierno de la infancia en la era de los derechos. Prácticas locales de "protección y restitución de derechos de niños, niñas y adolescentes" en dos municipios del conurbano bonaerense (Doctoral dissertation, Tesis de Doctorado en Ciencias Sociales). No publicada. Universidad de Buenos Aires.

Marín, D. L. (2011) Notas para Pensar la Constitución de un Campo Discursivo. En: "Políticas Públicas para la Infancia”. Santiago de Chile: UNESCO p. 55-76.

Marín, D. (2012) Interés por el gobierno y gobierno a través del interés: constitución de la naturaleza infantil. Pedagogía y Saberes, (37), 37-48.

Mussetta, P. (2009). Foucault y los anglofoucaultianos: una reseña del Estado y la gubernamentalidad. Revista mexicana de ciencias políticas y sociales, 51(205), 37-55. 
Pagni, P. A. (2015) Do governo ao cuidado da infância na arte pedagógica. Michel Foucault: O governo da infância. Belo Horizonte: Autêntica, 305-322.

Papalini, V., Córdoba, M., y Marengo, L. (2012). Estudios de la gubernamentalidad: la subjetividad como categoría de la política. Astrolabio, (8).

Reyes López, D. C. (2012) Gubernamentalidad en la escuela: técnicas y capilaridades en el biopoder y la disciplina. Estudio de caso en un colegio de clase alta de la ciudad de Bogotá. Universidad Nacional de Colombia. Facultad de Ciencias Humanas. Maestría en Estudios Culturales. 156.

Runge Peña, A. K. (2016). De la calle a la casa, de la casa a la habitación y al centro comercial: espacios para la domesticación y el gobierno de la infancia contemporánea de Medellín. Cuadernos de Educação. Dossie, 55-76.

Runge, A. K., y Carrillo, S. C. (2013). Mega jardines infantiles: heterotopías para el gobierno de la población infantil en Medellín. Revista Colombiana de Educación, (65), 239-259.

Veiga-Neto, A. (2015). Por que governar a infância. Michel Foucault: o governo da infância. Belo Horizonte: Autêntica, 49-56.

Voltarelli, M. A., y Nascimento, M. L. (2019) A infância na América Latina: aportes do campo dos Estudos da Infância em Argentina, Brasil e Chile, Sociedad e Infancias, 3, 211-235. 